\title{
Recording of swallowing events using electromyography as a non-invasive measurement of salivation
}

Citation for published version (APA):

Nederkoorn, C., Smulders, F. T. Y., \& Jansen, A. (1999). Recording of swallowing events using electromyography as a non-invasive measurement of salivation. Appetite, 33(3), 361-369. https://doi.org/10.1006/appe.1999.0268

Document status and date:

Published: 01/01/1999

DOI:

10.1006/appe.1999.0268

Document Version:

Publisher's PDF, also known as Version of record

\section{Document license:}

Taverne

Please check the document version of this publication:

- A submitted manuscript is the version of the article upon submission and before peer-review. There can be important differences between the submitted version and the official published version of record.

People interested in the research are advised to contact the author for the final version of the publication, or visit the DOI to the publisher's website.

- The final author version and the galley proof are versions of the publication after peer review.

- The final published version features the final layout of the paper including the volume, issue and page numbers.

Link to publication

\footnotetext{
General rights rights.

- You may freely distribute the URL identifying the publication in the public portal. please follow below link for the End User Agreement:

www.umlib.nl/taverne-license

Take down policy

If you believe that this document breaches copyright please contact us at:

repository@maastrichtuniversity.nl

providing details and we will investigate your claim.
}

Copyright and moral rights for the publications made accessible in the public portal are retained by the authors and/or other copyright owners and it is a condition of accessing publications that users recognise and abide by the legal requirements associated with these

- Users may download and print one copy of any publication from the public portal for the purpose of private study or research.

- You may not further distribute the material or use it for any profit-making activity or commercial gain

If the publication is distributed under the terms of Article $25 \mathrm{fa}$ of the Dutch Copyright Act, indicated by the "Taverne" license above, 


\title{
Recording of Swallowing Events Using Electromyography as a Non-invasive Measurement of Salivation
}

\author{
C. NEDERKOORN, F. T. Y. SMULDERS and A. JANSEN \\ Department of Psychology, Maastricht University, The Netherlands
}

\begin{abstract}
The present study examined whether the measurement of swallowing activity by electromyography (EMG) provides a sensitive and valid method for the assessment of the amount of saliva secreted. Thirteen subjects tasted lemon juice and water, and smelled lasagna and hay, while the amount of saliva, measured with the aid of cotton dental rolls, was compared with the number of peaks in the EMG activity of the musculus digastricus. Swallowing indeed differentiated between the stimuli and the correlation between the number of swallows and the amount of saliva was significant. The present data suggest that monitoring the swallowing movement using EMG might be a sensitive, valid and reliable method for the measurement of salivary flow. The use is recommended for the measurement of salivation when a simple and non-invasive method is needed.
\end{abstract}

(C) 1999 Academic Press

\section{INTRODUCTION}

One of the main functions of saliva is to act as a lubricant, facilitating passage through the digestive tract; it also initiates digestive processes. Chemosensory stimulation (e.g. smell and taste) and the view of food are able to elicit an increase in salivary flow (Epstein et al., 1996; Wooley et al., 1976) which optimizes the digestion, absorption and use of ingested nutrients (Mattes, 1997). The anticipatory salivatory reaction to food cues is stronger when the subject is hungry or when the food is palatable (Franchina \& Slank, 1988; Hodgson \& Greene, 1980; Sahakian et al., 1981; Wooley \& Wooley, 1973, 1981; Wooley et al., 1976; Wooley et al., 1975). Obesity, dieting and eating disorders also influence salivatory responses to food cues (Epstein et al., 1996; Klajner et al., 1981; LeGoff et al., 1988; Wooley et al., 1976). For example, LeGoff et al. (1988) found that subjects with anorexia nervosa salivated less and subjects with bulimia nervosa salivated more when exposed to different food odours, compared to matched controls. Measurement of salivatory responses might therefore be an important tool for the investigation of eating behaviour. In other research areas too, the measurement of salivatory responses has been valuable. In the field of alcohol addiction, for example, salivation to alcohol cues has been used as an index of craving or cue reactivity (Cooney et al., 1984; Pomerleau et al., 1983; Walitzer \& Sher, 1990).

There are several techniques for the measurement of salivation. Some are not suitable in experiments on eating behaviour or craving for drugs because of their

The authors acknowledge with gratitude the technical support of Huub Hamers.

Address correspondence to: Chantal Nederkoorn, Maastricht University, Dept. of Psychology, P.O. Box 616, 6200 MD Maastricht, The Netherlands. E-mail: c.nederkoorn@psychology.unimaas.nl 
invasive characteristics. For example, measurement by the insertion of a cannula into the various ducts of the salivary glands is laborious and painful (Gormezano, 1966; White, 1977). Measurement with Lashley's disk may also cause discomfort (Gormezano, 1966) and does not tap all sources of saliva. Moreover, it is unpleasant for subjects to void saliva; the method does not allow online monitoring and thus requires interruption of the experiment. The ideal technique is non-invasive, does not interfere with appetite or craving for drugs, permits study of the change in salivary flow over time and minimizes the influence of demand characteristics and expectancies, which are also found to influence the salivatory response (Siegel \& Hagen, 1982). It will therefore be a great advantage if subjects are not aware of the measurement of their salivation.

An easy and frequently used method is the absorption of saliva by rolls of cotton. According to the Strongin, Hinsie and Peck (SHP) technique (White, 1977), two rolls are placed buccally and one sublingually. The weight of the rolls is determined before and after the period of measurement. The cotton roll method has proven to be a reliable, valid and sensitive technique: White (1977) showed that measurements with cotton rolls correlated strongly with Lashley's disks measurements. Other researchers were able to distinguish adequately salivatory responses to diverse stimuli (Drummond, 1995; Epstein et al., 1992; Epstein et al., 1995; LeGoff et al., 1988; Pomerleau et al., 1983; White, 1977). However, the dental roll method also has disadvantages: the monitoring of changes in salivary flow over periods shorter than $2 \mathrm{~min}$ is less sensitive (Epstein et al., 1995); also in order to insert and to remove the dental rolls, it is necessary to interrupt the experimental procedure. Furthermore, it is rather unpleasant to keep dental rolls in one's mouth and this might interfere with appetite. Finally, the pressure of the dental rolls in the salivary glands can itself provoke a salivary response, thus affecting the reliability of the experimental data.

A completely different technique is to measure the frequency of swallows as an estimate of amount of saliva. The frequency of swallowing can be determined by counting peaks of electromyographic activity of the musculus digastricus. This swallow technique allows the monitoring of time courses and is not invasive or reactive. Kapila et al. (1984) found that the rate of spontaneous swallowing appeared to be influenced directly by salivary flow. They showed that surface electrodes placed on the larynx could measure swallowing activity adequately when the subjects did not move their mouth or jaws. Consequently, the method cannot be used during the act of eating. However, both alcoholics and controls were found to swallow more during exposure to their favourite alcoholic beverage than when smelling cedar chips (Kaplan et al., 1985) and alcoholics swallowed more often than non-alcoholics in response to their favourite alcohol beverage relative to a control stimulus (Pomerleau et al., 1983). In a validation study (Pomerleau et al., 1983) the change in swallowing and the change in amount of saliva measured with dental rolls were significantly correlated $(r=0 \cdot 69)$. Unfortunately, this was the only study in which swallowing was compared with another method of measuring saliva and no details are given about the method of measurement. Furthermore, only alcoholics were included, who were exposed to their favourite beverage to provoke saliva.

Because of the obvious advantages of the swallowing technique over others, it is worthwhile examining its validity and sensitivity in a sample of normal subjects, utilizing various foods and other cues. In the present study, two salivation-provoking stimuli (lemon juice and lasagna) and two control stimuli (water and hay) were presented. If the swallowing method is sensitive, it should be able to discriminate 
between these stimuli. Correlation with the dental roll technique was used as an index of criterion-validity, whereas correlation between repeated measurements was used to examine the reliability of the new method.

\section{METHOD}

\section{Participants}

Sixteen women participated in the experiment. Only dietarily unrestrained women were invited to participate, because dieting and eating disorders might influence salivatory responses (LeGoff et al., 1988). The subjects were instructed not to eat or to drink coffee in the $4 \mathrm{~h}$ before the experiment. All subjects had a normal weight \{mean Body Mass Index [BMI, weight $(\mathrm{kg}) /$ height $\left.^{2}(\mathrm{~m})\right]=21.9$, standard error of mean $(S E M)=0 \cdot 4\}$ and mean age was $20 \cdot 7$ (range 19-24). None of the subjects reported having a cold or having trouble with smelling the stimuli. No one suffered from hay fever or used any medication known to influence saliva production.

\section{Questionnaires}

As part of another study, all first grade students of the department of psychology of the Maastricht University completed a set of questionnaires, one of which was a Dutch translation of the Restraint Scale (RS; Herman \& Polivy, 1980). The RS is a self-report questionnaire consisting of 10 items assessing attitudes towards weight and eating, degree and frequency of dieting and weight fluctuations. The RS is reliable and valid in normal-weight samples, its test-retest reliability is high and the internal consistency is good (Cronbach's alpha $=0.86$; see Ruderman \& Besbeas, 1992). The scale has high predictive validity; it is a good predictor of eating behaviour in normal-weight individuals in a variety of situations (Gorman \& Allison, 1995; Heatherton, et al., 1988). Subjects with scores lower than 12 were considered unrestrained (based on the mean score of 269 Dutch female students; Overduin \& Jansen, 1996), and they were invited to participate. In addition, line ratings were used to assess hunger, ranging from 0 (not hungry at all) to 100 (very hungry), and liking for lasagna $(0=$ not at all, $100=$ very much). Finally, a questionnaire enquired about compliance with the instructions, ability to smell and use of medication.

\section{Stimuli}

The experimental gustatory stimulus was $0.3 \mathrm{ml}$ lemon juice, administered by drops on the middle of the tongue. The control stimulus was $0.3 \mathrm{ml}$ non-carbonated mineral water, also administered in drops. The lemon juice and the mineral water were both at room temperature. The experimental olfactory stimulus was the sight and smell of a plate with $500 \mathrm{~g}$ lasagna, heated in a microwave. The control stimulus was a plate with hay on it.

\section{Measures}

Three dental rolls were used (Hartman nr.2, $10 \times 35 \mathrm{~mm}$ ), one placed sublingually and two placed buccally. The weight of the three dental rolls in a little plastic bag 
(a)
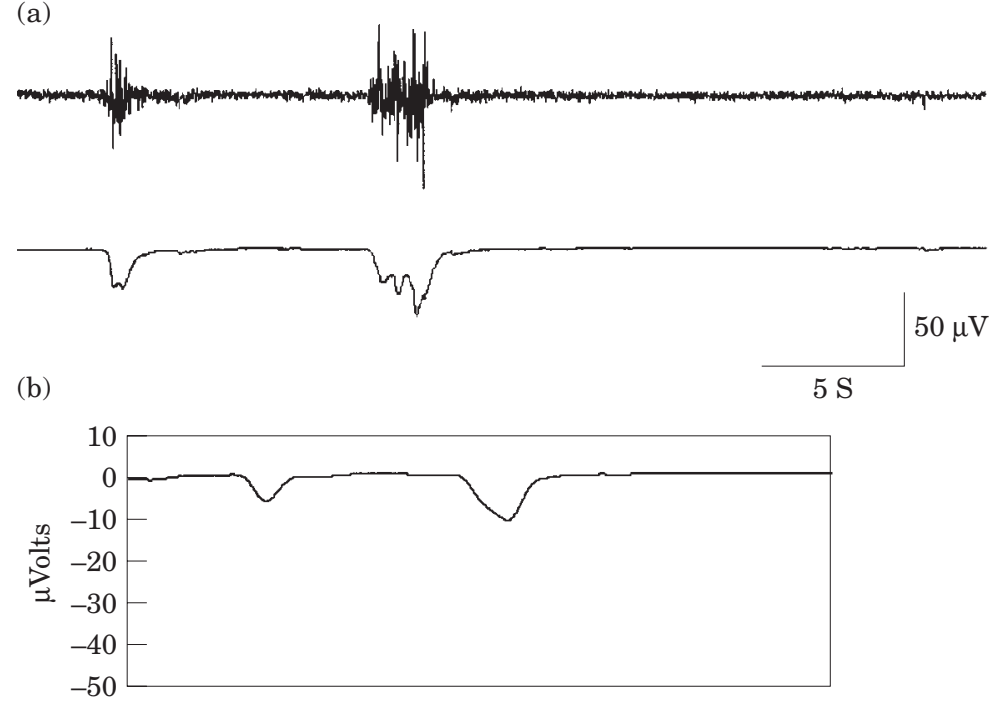

FIGURE 1. Example of two swallows, in epoch of $30 \mathrm{~s}$. (a) upper line is raw EMG, bottom line is rectified and integrated EMG; (b) depicts signal after resampling, filtering and baseline subtraction. Both peaks are larger than the threshold and identified as swallows.

was determined before the experiment. At the end of each measurement episode, the subjects were instructed to take the rolls carefully with their fingertips and to put them back in the plastic bag as quickly as possible. Then they sealed the bag. The weight was determined again after the experiment and the gain in weight was calculated. Maximum absorption possible with the three dental rolls was approximately $10 \mathrm{~g}$. The maximum weight measured in this experiment was $8.45 \mathrm{~g}$; therefore, complete saturation was not reached.

Swallowing was measured by $\mathrm{Ag}-\mathrm{AgCl}$ electrodes (diameter $11 \mathrm{~mm}$, SensorMedics). Two electrodes were attached under the left jaw, lengthways along the anterior part of the musculus digastricus, at a distance of $1.0-1.5 \mathrm{~cm}$ from each other, and a reference electrode was placed on the left mastoid process. EMG activity was recorded using a Psylab Bio-Amplifier, with a band pass filter set between 10 and $300 \mathrm{~Hz}$. The signal was rectified online and integrated (using Psylab Rectifier/ Integrator) with time constant set at $200 \mathrm{~ms}$ and digitized $(12 \mathrm{bit}, 500 \mathrm{~Hz})$ on a personal computer. EMG was recorded for 2 min after each stimulus. The integrated EMG data were used for further analysis. First, the data were resampled at $20 \mathrm{~Hz}$ by replacing every 25 samples by the mean value of these samples, in order to reduce the number of data points. The epochs were then lowpass filtered at $0.036 \mathrm{~Hz}(-3 \mathrm{~dB}$, Ruchkin \& Glaser, 1978), and the mean level of an epoch was substracted as baseline. An example of a swallow, before and after these transformations, is depicted in Fig. 1. From this smoothed signal, the computer detected every peak (defined as a sample flanked by samples with lower values). Close visual inspection of pilot swallow measurements led to the definition of a swallowing response being an integrated signal response above the threshold of $3.8 \mu \mathrm{V}$, with a minimum of $1.5 \mathrm{sec}$ between responses. During the recordings, artifacts like coughing were noted down by the experimenter. Epochs with artifacts were not analysed. All signals were also visually 
examined, and the first author counted the number of apparent swallows, after the removal of any cues that indicated the experimental conditions. The correlation between visual and automatic analyses of swallowing was significant over all (104) records $(r=0 \cdot 90, p<0 \cdot 001)$. The results yielded by the automatic detection were used for further processing.

\section{Procedure}

After the subject entered the laboratory, the electrodes were attached and the signal was checked. Then the subject was instructed to rate her hunger and to practice with the insertion and removal of the dental rolls, including putting them back in the plastic bag and sealing it. The subject was asked to sit quietly and to relax during the measurements, without talking or moving, in order to diminish movement artifacts. A baseline EMG record of 4 min was made during which saliva was simultaneously measured with the dental roll method. Then the subject received each stimulus in turn, together with new dental rolls. She was instructed to concentrate on the taste or the smell of the stimuli. The order of presentation of the two pairs of stimuli was counterbalanced. After each recording the subject rinsed her mouth with $30 \mathrm{ml}$ of mineral water and a 2-min pause followed.

Because dental rolls absorb saliva, their presence might dimish the frequency of swallowing. The pressure of the rolls on the cheeks is also able to influence production of saliva. Therefore, the whole procedure was repeated without dental rolls being inserted. The order of measurement with and without dental rolls was counterbalanced. At the end of the experiment, the subject filled out the questionnaires; her weight and height were measured and she received payment.

\section{Results}

\section{Subject characteristics}

All subjects but one reported that they compiled with the instructions neither to eat nor to drink coffee for $4 \mathrm{~h}$ before the experiment. The data of this one subject were excluded from analysis. Two subjects reported a strong dislike for lasagna (scores 24 and 38) and they did not sit quietly while smelling the lasagna. Their data were also excluded from analysis. The remaining subjects $(N=13$, mean $\mathrm{BMI}=21 \cdot 6$, $S E M=0 \cdot 39$; mean age $=21, S E M=0 \cdot 41)$ rated a liking for lasagna (mean score = $77 \cdot 8, S E M=4)$ and were moderately hungry (mean score $=55 \cdot 4, S E M=5 \cdot 5$ ). The mean Restraint Score of these 13 subjects was $7 \cdot 7(S E M=0 \cdot 7)$.

\section{Dental rolls}

Subjects salivated significantly more when tasting lemon juice than when tasting water (Fig. 2a), $t(12)=14 \cdot 7, p<0 \cdot 001$. The subjects also salivated more when they were exposed to lasagna than when they were exposed to hay, $t(12)=2 \cdot 3, p<0 \cdot 05$.

\section{Swallowing}

Subjects swallowed significantly more after tasting lemon juice than after tasting water $F(1,12)=50 \cdot 1, p<0 \cdot 001$ (Fig. 2). Insertion of dental rolls had no significant 

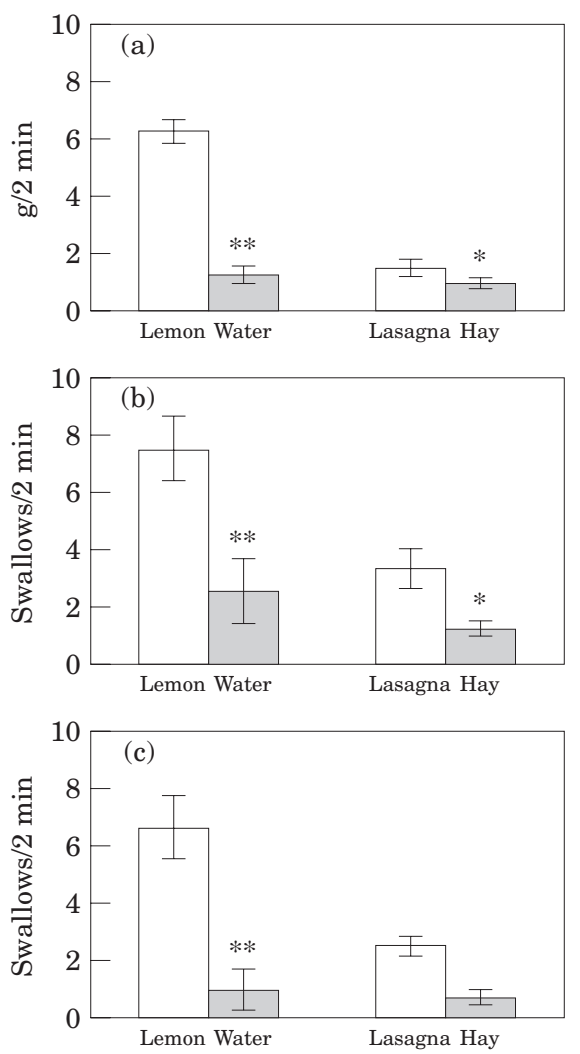

FIGURE 2. Reactions to the different stimuli, measured by (a) dental rolls, (b) swallowing without dental rolls and (c) swallowing with dental rolls, with the standard error of means $(S E M \mathrm{~s}) .{ }^{*} p<0.05,{ }^{* *} p<0.01$.

effect on the number of swallows during the gastatory stimuli and there was no significant interaction effect. However, during exposure to the olfactory stimuli subjects swallowed less when the dental rolls were inserted, $F(1,12)=6 \cdot 9, p<0 \cdot 05$. There was also a significant interaction effect: the difference between lasagna and hay was larger without than with dental rolls present, $F(1,12)=12 \cdot 1, p<0 \cdot 005$. Post hoc $t$-tests revealed that the difference in swallows between lasagna and hay was significant in the absence of dental rolls, $t(12)=3 \cdot 1, p<0 \cdot 05$, but not when dental rolls were inserted, $t(12)=0 \cdot 64$. Generalizing over all stimuli, subjects swallowed more in the absence of dental rolls than in their presence, $t(51)=2 \cdot 4, p<0 \cdot 05$.

\section{Correlation of measurements}

To validate the use of swallows as an index of saliva, the correlation with weight of saliva collected in dental rolls was calculated. Data for all four stimuli were included in the correlation $(N=13$ subjects $\times 4$ stimuli $=52)$. Weight gain of dental rolls correlated with number of swallows in absence of dental rolls, $r=0.57, p<0 \cdot 001$, 

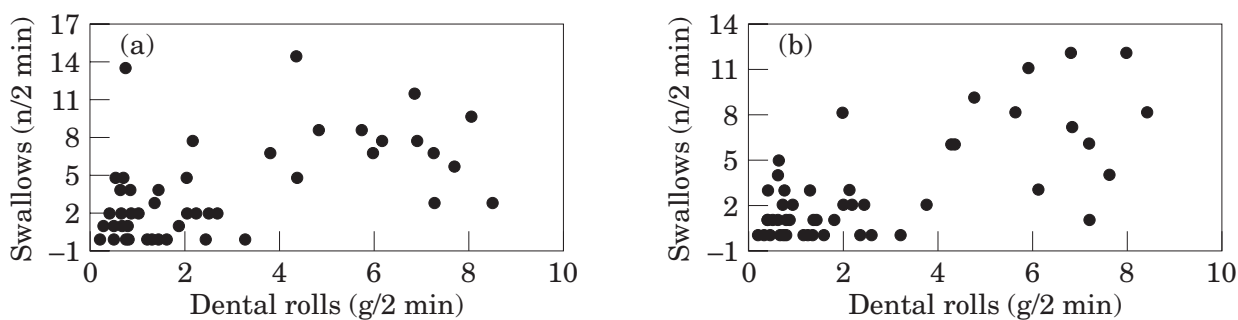

FIGURE 3. Correlation between increase in weight of dental rolls and number of swallows, (a) measured without and (b) with dental rolls inserted, as response to four different stimuli.
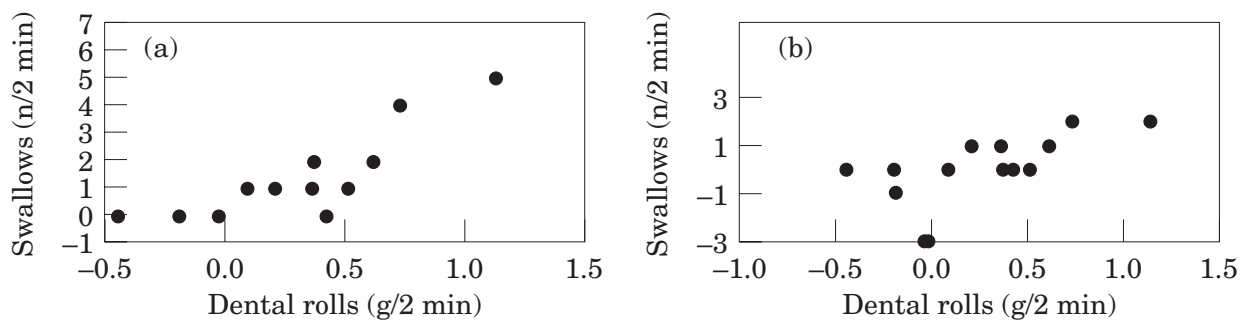

FIGURE 4. Correlation between increase in weight of dental rolls and number of swallows, measured (a) without and (b) with dental rolls inserted, as response to lasagna minus hay.

and with number of swallows with dental rolls inserted, $r=0 \cdot 72, p<0 \cdot 001$ (Fig. 3).

For experimental study of influences on eating behaviour, changes in saliva flow need to be measured. Therefore, the change in salivatory response to control and experimental stimuli (measured with dental rolls) was correlated with the change in the number of swallows between the control and experimental conditions, subtracting effects of the control stimuli from effects of the experimental stimuli, as in Pomerleau et al. (1983). In the lemon juice minus water condition, the change in salivation measured by dental rolls did not correlate significantly with the change in the number of swallows $(r=0 \cdot 19$ without and $r=0 \cdot 23$ with dental rolls). In the lasagna minus hay condition, however, the change in salivation measured with dental rolls correlated significantly with the change in number of swallows measured either without dental rolls $(r=0.85, p<0 \cdot 01)$ or with dental rolls in place $(r=0 \cdot 65, p<0.05)$; see Fig. 4 .

Test-retest reliability was determined by computing the correlation between measurements of the number of swallows with and without dental rolls inserted, including all the stimuli $(N=52)$. This correlation was highly significant $(r=0 \cdot 74$, $p<0 \cdot 001)$. Separate correlations for each stimuli yielded the same results.

\section{DisCUSSION}

These results indicate that electrophysiological measurement of swallowing is a sensitive, valid and reliable index of the amount of saliva produced in response to food stimuli. Swallowing occurred more often during the tasting of lemon juice than 
it did with water, in both the absence and the presence of dental rolls. Without dental rolls, the subjects swallowed more during exposure to lasagna than they did to hay, although this effect disappeared in the presence of dental rolls. The measurement of swallowing is thus a sensitive method, especially when no dental rolls are inserted. Test-retest correlation shows that the method is also reliable.

Correlation between the number of swallows and the amount of saliva over all stimuli showed that the electromyographic method is valid. A closer look at the data, however, shows that the correlation using the lasagna minus hay value is significant whereas it is not with the lemon juice minus water value. This may be because lemon juice is such a strong stimulus that it provokes contractions of muscles in and near the mouth which are unrelated to swallowing. So, electromyography may be most useful for research into foods and drinks which do not elicit such contractions.

A limitation to the method is that validity is diminished in situations where movement artifacts cannot be prevented and during strong stimuli such as extreme sourness. In these instances, other methods (like use of Lashley's disk) must be considered. In other cases, the electromyographic method has the advantages over cotton rolls that measurements are not invasive, will not provoke salivary reactions on their own, do not interfere with appetite or craving, and enable the study of changes in salivary flow over time. The method might prove to be useful, therefore in the study of influences on human responses to food (e.g. anticipation, cue reactivity, cue exposure), eating disorders and addictive behaviour.

\section{REFERENCES}

Cooney, N. L., Baker, L. H., Pomerleau, O. F. \& Josephy, B. (1984). Saliva to drinking cues in alcohol abusers: Toward the validation of a physiological measure of craving. Addictive Behaviors, 9, 91-94.

Drummond, P. D. (1995) Effect of imagining and actually tasting a sour taste on one side of the tongue. Physiology and Behavior, 57, 373-376.

Epstein, L. H., Rodefer, J. S., Wisniewski, L. \& Caggiula, A. R. (1992) Habituation and dishabituation of human salivary response. Physiology and Behavior, 51, 945-950.

Epstein, L. H., Wisniewski, L., deFlavia, P. \& Mitchell, S. (1995) Salivary responding and the duration of measurement. Behavior Research Methods, Instruments and Computers, 27, 379-382.

Epstein, L. H., Paluch, R, \& Coleman. (1996). Differences in saliva to repeated food cues in obese and nonobese women. Psychosomatic Medicine, 58, 160-164.

Franchina, J. J. \& Slank, K. L. (1988) Effects of deprivation on salivary flow in the apparent absence of food stimuli. Appetite, 10, 143-147.

Gorman, B. S. \& Allison, D. B. (1995). Measures of restrained eating. In D. B. Allison (Ed.), Handbook of assessment methods for eating behaviors and weight-related problems. California: Sage Publications.

Gormezano, I. (1996). Classical conditioning. In J. B. Sidowski (Ed.), Experimental methods and instrumentation in psychology, pp. 383-421. New York: McGraw-Hill Book Company.

Heatherton, T. F., Herman, C. P., Polivy, J., King, G. A. \& McGree, S. T. (1988). The (mis)measurement of restraint: An analysis of conceptual and psychometric issues. Journal of Abnormal Psychology, 97, 19-28.

Herman, C. P. \& Polivy, J. (1980) Restrained eating. In A. B. Stunkard (Ed.), Obesity, pp. 208-255. Philadelphia: Saunders.

Hodgson, R. J. \& Greene, J. B. (1980) The saliva priming effect, eating speed and the measurement of hunger. Behaviour Research and Therapy, 18, 243-247.

Kapila, Y. V., Dodds, W. J., Helm, J. F. \& Hogan, W. J. (1984) Relationship between swallow rate and salivary flow. Digestive Diseases and Science, 29, 528-533. 
Kaplan, R. F., Cooney, N. L., Baker, L. H., Gillespie, R. A., Meyer, R. E. \& Pomerleau, O. F. (1985). Reactivity to alcohol-related cues: Physiological and subjective responses in alcoholics and non-problem drinkers. Journal of Studies on Alcohol, 46, 267-272.

Klajner, F., Herman, C. P., Polivy, J. \& Chhabra, R. (1981). Human obesity, dieting, and anticipatory saliva to food. Physiology and Behavior, 27, 195-198.

LeGoff, D. B., Leichner, P. \& Spigelman, M. N. (1988) Salivary response to olfactory food stimuli in anorexics and bulimics. Appetite, 11, 15-25.

Mattes, R. D. (1997). Physiologic responses to sensory stimulation by food: Nutritional implications. Journal of the American Dietetic Association, 97, 406-410, 413

Overduin, J. \& Jansen, A. (1996). A new scale for use in non-clinical research into disinhibitive eating. Personality and Individual Difference, 20, 669-677.

Pomerleau, O. F., Fertig, J., Baker, L. \& Cooney, N. (1983). Reactivity to alcohol cues in alcoholics and non-alcoholics: Implications for a stimulus control analysis of drinking. Addictive Behaviors, 8, 1-10.

Ruchkin, D. S. \& Glaser, E. M. (1978). Simple digital filters for examining CNV and P300 on a single-trial basis. In D. A. Otto (Ed.), Multidisciplinary perspectives in eventrelated brain potential research. EPA-600/9-77-043, pp. 579-581. Washington, D.C.: U.S. Government Printing Office.

Ruderman, A. J. \& Besbeas, M. (1992). Psychological characteristics of dieters and bulimics. Journal of Abnormal Psychology, 101, 383-390.

Sahakian, B. J., Lean, M. E. J., Robbins, T. W. \& James, W. P. T. (1981). Saliva and insulin secretion in response to food in non-obese men and women. Appetite, 2, 209-216.

Siegel, W. E. \& Hagen, R. L. (1982). The influence of demand characteristics and expectancies in the measurement of salivary response. Journal of Behavioral Assessment, 4, 179-185.

Walitzer, K. S. \& Sher, K. J. (1990). Alcohol cue reactivity and ad lib drinking in young men at risk for alcoholism. Addictive Behaviors, 15, 29-46.

White, K. S. \& Sher, K. J. (1977). Saliva: A review and experimental investigation of major techniques. Psychophysiology, 14, 203-212.

Wooley, O. W. \& Wooley, S. C. (1981). Relationship of saliva in humans to deprivation, inhibition and the encephalization of hunger. Appetite, 2, 331-350.

Wooley, S. C. \& Wooley, O. W. (1973). Saliva to the sight and thought of food: a new measure of appetite. Psychosomatic Medicine, 35, 136-142.

Wooley, O. W., Wooley, S. C. \& Williams, B. S. (1975). Saliva as a measure of appetite: Studies of the anorectic effects of calories and amphetamine. In Novin, D., Wyrwicka, W. \& Bray, G. (Eds), Hunger: Basic mechanisms and clinical implications, pp. 421-429. New York: Raven Press.

Wooley, O. W., Wooley, S. C. \& Dunham, R. B. (1976). Deprivation, expectation and threat: Effects on saliva in the obese and nonobese. Physiology and Behavior, 17, 187-193.

Received 21 December 1998, revision 24 May 1999, accepted in revised form 9 July 1999 